\title{
Subliminal Messages - Unconsciuosly Perceived Sensations and Study Research on Subliminal Knowledge
}

\author{
Branislav R. Tanasic
}

\section{ABSTRACT}

\begin{abstract}
Some content can be so well crafted that consumers are not aware that they are actually part of the promotion activity. The message is concealed, transformed, and communicates with consumers with associative connections at the subconscious level. Subconscious communication is a technique that marketers will use more and more, so in the design and realization of promotional activities, they combine the knowledge of other sciences and the latest technological inventions. Subconscious communication is often far more effective than direct addressing, provoking, and causing the desired effect, sometimes completely contrary to what the content posted seems to indicate. Content placed so as to address consumers at the subconscious level is called subliminal messages or subliminal. Very weak signals, stimuli below the threshold of conscious perception are not registered consciously. It is especially important to note that reason cannot resist this type of message because it is not recognized, it is circumvented even in the stage of stimulus. This is the main danger of subliminal messages; bypassing reasoning insert direct information in a mind that cannot be confronted. This is a very unusual method of manipulative persuasion technique for individuals and the masses exposed to the effects of subliminal marketing.
\end{abstract}

Keywords: Communications, messages, stimuli, subconscious, subliminal.
Submitted : March 26, 2021

Published : April 19, 2021

ISSN: $2593-8339$

DOI: 10.24018 /ejmed.2021.3.2.786

Branislav R. Tanasic, $\mathbf{P h D}$

University of the People, Sabac, Serbia, and Faculty of management - FAM, Sremski Karlovci, Serbia.

(e-mail: tanasicbrana ${ }^{\circledR}$ yahoo.com)

\section{INTRODUCTION}

Vance Packard book Hidden Persuaders, explores the psychological side of subconscious manipulation of the masses, reveals manipulative methods and says that companies are undertaking large scale efforts to channel subconscious minds, based on the knowledge of psychology and other sciences purchasing decisions and way of thinking. Packard then emphasizes typically these efforts take place beneath the level of awareness, so that they are often in a sense hidden. The result is that many are being influenced and manipulated, far more than realize, in the patterns of everyday lives [1].

Regardless of the time and applied methods of distribution of propaganda messages, the goal is to draw the consumer's attention to the product/service. A modern man is exposed to the influence of an extraordinary amount of different information, and it is increasingly difficult to keep attention on the brand or product using traditional promotional means. A conscious sphere of the brain in craving stimulus situations activates defense mechanisms that discard data classified as irrelevant information by forming physiological and psychological filters [2]. In addition to direct communication at the conscious level, with consumers or better to say to consumers, it can influence the subconscious level of perception. In order to better understand subliminal stimuli, in the next chapter will be worked out the process of conscious perception.

\section{PERCEPTION}

Perception, (Lat. Perceptio), is an extremely complex process, starting from the stimulus to the perception, that is, the conscious understanding of the environment. Perception is a thoughtful sum of all modalities of observation, that is to say, perception is a mentally-experiential arrangement of sensory impressions [3]. Perception is the process by which the brain arranges the data received from various receptors and interprets them in a meaningful and comprehensible whole. It is not a simple, passive reflection of objective reality, perception implies actively connecting sensory data with previous experience, comparing them, categorizing, verifying, which leads to a subjective experience of stimulus or more stimulus from the environment.

Although observations are traditionally regarded as passive, studies of illusions and ambiguous images, show that the perceptual brain system is active, ready to create a sense of the stimulus even in the sphere of unconsciousness. From 
this, it can be concluded that even if the perceptual processes take place at the level of the unconscious, the individual eventually has a full and developed awareness of the processes in the environment. It is important to emphasize here that perception is not a mere sum of different observations, it is much more, otherwise, everyone in the same stimulating situation would have the same perception, the same experience. Fortunately, is not so, and the same stimulating elements in each individual get a different meaning, personal seal, individual experience.

\section{SUBLIMINAL}

There are stimuli that are of very low intensity or occur very quickly, so they are below the limit of conscious observation. Such stimuli are called subliminal stimuli [4]. Subliminal is the union of two Latin words $s u b$ - below, and limen - threshold, means the content below the threshold [5]. Subliminal are messages below the boundary of conscious perception, which receptors or brain cannot consciously notice, that is, "in the subliminal study, the threshold is the level of stimulus that the respondent is unaware of, he does not know that the stimulus was at all" [6].

Psychologists noted at the end of the nineteenth century that stimuli below the threshold of conscious perception, meaning subliminal stimuli, also trigger sensory processes and as such have been registered [7].

The first documented experiments of the perception of the unconscious, Perception without awareness, are collections of works by the philosophers of Peirce and Jastrow, (Charles S. Peirce and Joseph Jastrow) from Hopkins University, published as early as 1884 . Pierce was interested in the psychophysical problem of self-noticeable difference, (justnoticeable difference, JND), or differential tin. He wanted to know what would happen if the differences between the stimuli were below what Weber \& Fechner characterized as a psychological threshold, or an absolute threshold [8].

They explored their own abilities to discern small differences in the pressure on their fingers and found that the accuracy of the decisions made was mathematically expected, even when they were convinced that they were only guessing about it. The researchers say that experimented with a sense of pressure, looking at the relationship of errors between the estimates that are two times higher than the pressure [8].

Pioneers in the field of unconscious perception stepped into the new psychological area, opened the door to the subconscious. This way, Edward W. Scripture began, when he published the book The New Psychology, in 1897, what Pirs and Jastrow had hinted, the Scripture clearly proved, especially through the study of unconscious movements [9]. An advocate of experimental research, he argued that "when a researcher studies a phenomenon, he cannot achieve more than superficial knowledge if he waits for an event to come to him. To get more information about the event, he must take an active role" [9]. Shortly thereafter, Boris Sidis published the book The Psychology of Suggestion, 1898, which states: "The subject of this book is the study of the subconscious, normal and abnormal, individual and group, the relations of suggestion and suggestiveness" [10].

In the study of subconscious perception, Sidis organized numerous experiments. He based one of the experiments by placing a card with a number or a letter, at a distance from which the respondents could not see what was written, or how they claimed to see only a blotchy spot. He used five cards with printed capital letters B, Z, K, U, H and numbers 2, 4, 5, 7 , and 9 . He asked the experimenters to read what they saw, or thought to see, to test the possibility of perception despite the fact that the respondent claims that he cannot clearly discern what is written on the cardboard. The results were surprising. Compared to accidentally accurate responses to blind - closed eyes, respondents who watched cartons had a far greater percentage of accuracy. In other words, despite the subjective inability to consciously experience the observation, a high degree of correct response is the result of the impulses that the subjects received subconsciously subliminally. The initiated sensory processes were not aware observed, but that is why the subconscious has properly registered most of the stimuli that have been created. Sidis comments on the results obtained: "All these experiments are proof of the presence of a secondary subconscious observation when the primary consciousness is not in the state" [10].

In the introductory part of his book, Psychology of Suggestion, Sidis are hoping that his work will be interesting not only for the careful reader but for stimulating it to be practically applied in life [10]. Sidis's vision of practical application, will have its fulfillment only half a century later, through an experiment carried out by James Vicary during the Picnic movie screening. With the help of tachistoscope, he designed the subliminal message screen: Hungry? eat popcorn and Thirsty? Drink Coca-Cola ", every 5 seconds for 3/1000parts of a second [11]. Subliminal advertising became known to the general public when Vicary summoned a press conference after six weeks and unveiled the results of his unique experiment. Although the press conveys the claim that the sale of popcorn has increased by $18.1 \%$ and Coca-Cola by $57.5 \%$, Vicary officially does not publish the results or the methodology of the conducted experiment, arguing that these are details of a confidential patent [12].

Even the fact that Vicary later renounced his findings did not influence the reduction of the public's belief in their propaganda effect. Americans spent about \$ 50 million a year on various audio products with allegedly suggestive subliminal messages that can help reduce weight, quit smoking, or increase intelligence [13]

Almost sixty years after the famous Vicary still a controversial cinema experiment, Cooper J. and Cooper G. organized a research in which they subliminally admired, the image of the Coca-Cola Coke and the word thirsty, tried to provoke the desire for a drink. It has been confirmed that subliminal manipulation has a positive effect on subjects who have declared themselves thirsty [14].

A group of scientists is conducting similar research. They showed that the subliminal stimulus of the branded Lipton Ice positively influences the choice of subjects to drink Lipton tea, but only if it is thirsty [15].

In the case of a choice between a commonly used brand and someone else subliminally propagating, there is an increased choice for a brand placed as a subliminal. Researchers also emphasize the importance of quality subliminal content as a prerequisite for positive effect, but also the consent of a subliminal message with the main goal 
of the respondents for example, the determination to purchase a particular product: "Despite many years of controversy, recent research shows that, if the goal is relevant, subliminal advertising can be feasible" [16].

The results of the electroencephalographic study of the correlation of the cerebral response to subliminal stimuliemotional facial expressions, [17], then EEG-controlled verification of the brain response, induced by subliminal words, [18], the influence of subliminal messages.

The study of the association of subliminal stimuli (words emitted below the threshold of conscious perception) and motor activity of the hand shows that motor processes are modulated by words as a result of mental projections of described movements, despite the fact that verbal stimuli are perceived unconsciously [19]. The unequivocal evidence of this claim is the electroencephalographic scanning of researchers that confirm the presence of a brain response to subliminal stimuli [20].

Subliminal are stimuli below the sensitivity threshold or absolute tin, they are not perceived consciously, but are registered at the level of the subconscious and as such they are stored. The controversial field of psychology, subliminal are a result of numerous scientific papers and discussions. The development of neuromarketing has enabled brain scanning to provide a direct insight into subliminal activity. Neuromarketing experiments are gathering solid, scientifically based data on brain reactions to stimuli, including subliminal: "Recent studies with the application of fMRI show that subliminal stimulus activates specific parts of the brain, despite the fact that the respondent is an unconscious stimulus" [21]. Experiments carried out with the help of fMRI (Functional Magnetic Resonance) of EEG, electroencephalograph and similar devices have unambiguously demonstrated the presence of the brain response of the respondent to subliminal stimuli.

In order to investigate the impact of a health warning sticker on cigarette packets, neuromarketing research was organized. In the final part of the work titled What is actually the warning label on the package of cigarettes? Tanasic concludes that neuromarketing is flawless proved that the label does not discourage smokers from tobacco but strongly stimulates the desire to light up a new cigarette. All the above leads to the conclusion that the etiquette is actually a hidden message where smokers cannot resist, and this is a feature of a first-class subliminal message. Small warning label ended a great job [22].

\section{Study RESEARCH ON SUbliminal KNOWLEDGE}

In order to determine the level of subliminal knowledge, research was organized. The survey involved 3700 respondents, 2,430 women, or $65.7 \%$ and 1270 men, which is $34.3 \%$. The age structure is the follows: the most represented is a category of young people up to 35 years of age, a total of 3030 or $81.9 \%$, of which the age group is up to 20 years old, it is represented by 540 or $14.6 \%$, and persons classified in the category from 20 to 35 years 1760 or $47.6 \%$ of respondents. The first look at Table I, shows that girls and women took much more participation in the research. The female population responded to the survey with 2430 representatives, or $64 \%$, while men reported 1370 times, in percent $36 \%$.

TABLE I: GENDER STRUCTURE AND YEARS OF LIFE

\begin{tabular}{cccccc}
\hline & Up to & $20-35$ & $35-50$ & $50-65$ & Total \\
\hline 20 year & 20 & 660 & 540 & 0 & 1270 \\
Female & 70 & 1100 & 730 & 130 & 2430 \\
Total & 540 & 1760 & 1270 & 130 & 3700 \\
\hline
\end{tabular}

The crucial question of research: Do you know what is subliminal messages? (Table II).

\begin{tabular}{ccc}
\multicolumn{2}{c}{ TABLE II: DO YOU KNOW WHAT IS SUBLIMINAL MESSAGES? } \\
\hline Answers & Frequency & Percent \\
\hline I know & 1440 & $38.9 \%$ \\
I heard about & 440 & $11.9 \%$ \\
I do not know & 1820 & $49.2 \%$ \\
Total & 3700 & $100 \%$ \\
\hline
\end{tabular}

An interesting analysis of the relationship of using the Internet with knowledge of the subliminal. The assumption was that people who spend more time next to the computer screen, with the increase in time spent, will have a higher percentage of knowledge about subliminal, appreciating some kind of educational dimension of this electronic media. But the data completely denied this idea. There is an increase in the number of respondents who claim to know what subliminal is, with increasing time spent on the global network, but up to 5 hours along the computer. Users who are online for more than 5 hours a day have a drastic fall in the number of subliminal acquaintances (Table III). So, after looking at the results of the survey, it is thought that one of the questions should be formulated in that direction, that those who declare themselves to know what subliminal are, discover the sources of their knowledge.

TABLE III: USE OF INTERNET AND KNOWLEDGE OF THE SUBLIMINAL

\begin{tabular}{ccccc}
\hline & I know & $\begin{array}{c}\text { I heard } \\
\text { about }\end{array}$ & $\begin{array}{c}\text { I donn`t } \\
\text { know }\end{array}$ & Total \\
\hline Rarely used & $701.9 \%$ & $601.6 \%$ & $701.9 \%$ & $2005.4 \%$ \\
Upto 2 hs & $48013.0 \%$ & $1303.5 \%$ & $3308.9 \%$ & $94025.4 \%$ \\
Up to 5hs & $61016.5 \%$ & $2506.8 \%$ & $115031.1 \%$ & $201054.3 \%$ \\
More of 5hs & $2105.7 \%$ & $00.0 \%$ & $2707.3 \%$ & $48013.0 \%$ \\
Don't use & $701.9 \%$ & $00.0 \%$ & $00.0 \%$ & $701.9 \%$ \\
Total & $144038.9 \%$ & $44011.9 \%$ & $182049.2 \%$ & $3700100 \%$ \\
\hline
\end{tabular}

A certain number of people know subliminal and believe in their actions, some do not believe or just do not accept such a possibility of manipulating the mind. (Table IV) Subliminal are present in everyday life, they used and further research should be guided in this direction, especially, because it is now personalized goals. Unlike television or cinema, where the media addresses a wide population, through a personal computer or mobile phone it can be addressed directly to a specific subject, so that the impact on some important people can have extremely significant consequences.

TABLE IV: POSSIBILITY OF MANIPULATING THE MIND

\begin{tabular}{ccc}
\hline Answers & Frequency & Percent \\
\hline Yes & 1090 & $29.5 \%$ \\
Im not sure & 2220 & $60.0 \%$ \\
No & 390 & $10.5 \%$ \\
Total & 3700 & $1000 \%$ \\
\hline
\end{tabular}




\section{CONCLUSION}

Subliminal lead into the twilight zone, the crossed and unmarked paths of the mind, and there is no map for that area. It reminds on medieval doctors before finding a microscope and knowledge of bacteria and viruses, that fought against an invisible enemy for whom they do not even know it exists, perhaps only with the vague image of a certain perceptible healer-that there is something there. Indeed, after all, that has been said and written about subliminal, it is not easy to accept the knowledge that something we do not see, we do not hear, we are not aware of the presence, it is so effectively influential. So, after the innocent visit to the cinema and exposure to subliminal, a man goes home full of new ideas, convinced that it created by own mind. A brief review of the visionaries who have anticipated the introduction of psychology and other sciences in the propaganda for decades have shown a common view of the use of manipulative techniques in communication. Experiments conducted with the help of fMRI (Functional Magnetic Resonance Imaging) EEG - electroencephalograph, and similar devices, unequivocally proved the presence of the brain response of the subjects to subliminal stimuli. The potential strength of this psychological phenomenon is that the mind cannot oppose this message, because it does not recognize it, in fact, it does not know about it, the conscious part is bypassed even in the phase of stimulation. The human brain registers sublimate, the question remains to what extent can message placed in this way influence the thinking and decisionmaking of each individual?

\section{REFERENCES}

[1] Packard Vance, The Hidden Persuaders, London, Longmans, Green \& CO, 2007, page 31

[2] Jahn G. Robert \& Dunne J. Brenda, Sensors, Filters, and the Source of Reality, Journal of Scientific Exploration, Vol. 18, No. 4, pp. 547-570, 2004.

[3] Tanasic R. Branislav, Podsvesne poruke i marketing, Belgrade, Impact of Internet on Business Activities in Serbia and Worlwide Synthesis, pgs. 1023-1027, 2014.

[4] Loftus F. Elizabeth \& Klinger R. Mark, Is the unconscious smart or dumb? American Psychologist, 47 (6): 761-765, 1992.

[5] Merriam-Webster Dictionary, Subliminal, [online] Available, http://www.merriamwebster.com/dictionary/subliminal, $\left[\begin{array}{ll}26 . & 04\end{array}\right.$ 2020.].

[6] Chessman Jim \& Merkile M. Phillip, Priming with and without awerness, Perception and Psychophisics, 36 Vol. 4, page 385, 1984.

[7] Woodworth S. Robert, Reviewed Work: The Doctrine of Primary and Secondary Sensory Elements by Boris Sidis, The Journal of Philosophy, Psychology and Scientific Methods, Vol. 5, No. 17, 472474, Aug. 13, 1908.

[8] Jastrow Joseph \& Peirce Charls Sanders, On small differences of sensation, Memories of the National Academy of Science, 3 (1885), Presented: 17, October 1884.

[9] Scripture Edwar Wheler, TheNew Psychology, New York, Charles Scribner's Sons, pg. 53, 1897.

[10] Sidis Boris, The psycholohy of suggestion; a research into nature of man and society, New York, D. Appleton \& Company, pg. 3, 1898.

[11] Pratkanis R. Anthony, The cargo-cult science of subliminal persuasion, Skeptical Inquirer, 16, 260-272, 1992.

[12] Rogers Stuart, How a publicity blitz created the myth of subliminal advertising, Public Relations Quarterly, Vol. 37, (4), 12-17, 1992.

[13] Greenwald A. G., Spangenberg E. R., Pratkanis A. R. \& Eskenazy J. Double-blind tests of subliminal self-help audiotapes, Psychological Science, 2, 119-122, 1991.

[14] Cooper Joel, \& Cooper Grant, Subliminal motivation: A story revisited. Journal of Applied Social Psychology, Volume 32, pgs. 2213-2227, 2002.
[15] Karremans C. Johan, Stroebe Wolfgang, Claus Jasper, Beyond Vicary's fantasies: The impact of subliminal priming and brand choice, Journal of Experimental Social Psychology, Volume 42, pgs. 792-798, 2006.

[16] Verwijmeren Thijs, Karremans Johan, Stroebe Wolfgang, Wigboldus Daniel, The workings and limits of subliminal advertising: the role of habits, Journal of Consumer Psychology, Volume 21, Issue 2, 206-213, 2011.

[17] Prete Giulia, Capatopsto Paolo, Zappasodi Filippo, Laeng Bruno, Tommasi Luca, The cerebral correlates of subliminal emotions: an electroencephalographic study with emotional hybrid faces, Europan Journal of Neuroscience, 2015, 1-11. 2015.

[18] Gibbons Henning, Subliminal emotional wards: Insights from event related potentials and individual differences related to anxiety, Consciousness and Cognition, Volume 18, Issue 2, 384-400, 2009.

[19] Boulonger Veronique, Silber Y. Beata, Roy C. Alice, Paulignan Yves, Jeannerod Marc, Nazir, A. Tatjana, Subliminal display action word interferes with motor planing: A combines EEG and kinematic study, Journal of Physiology - Paris, Volume 102, Issues 1-3, 130-136, 2008

[20] Sperdin F. Holger, Spierer Lucas, Becker Robert, Michel M. Christoph, Landis Theodor, Submillisecond unmasked subliminal visual stimuli evoke electricalbrain responses, Human Brain Mapping, Volume 36, Issue 4, 1470-1483, 2014.

[21] Brooks S. J., Savov V., Allzen E., Benedict C., Fredrikson R., Schioth $\mathrm{H}$. B. Exposure to subliminal arousing stimuli induces robust activation in the amygdala, hippocampus, anterior cingulate, insular cortex and primary visual cortex: a systematic meta-analysis of fMRI studies, Neuroimage, 59 (3) 2962-2973, 2012.

[22] Tanasic R. Branislav, What is actually the warning label on the package of cigarettes? International Journal of Contemporary Research and Review, Volume 9, Issue 2, pgs. 20383-20392, 2018.

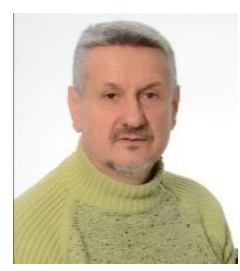

\section{Branislav R. Tanasic}

Narrower areas of interest are subliminal branding, subliminal marketing and neuromarketing. Has own EEG laboratory (Electroencephalographic laboratory), organized numerous neuromarketing research in order to better understand the subconscious reactions of consumers. In addition to papers on the impact of sensory branding on the decision-making process, conducted interesting and significant research on the impact of the health warning label on tobacco packets on smokers. Currently preparing to investigate the impact of binaural stimuli on cerebral hemispheric synchronization. Optained Ph.D. at the University of Business Studies in Banja Luka, dissertation topic: Neuromarketing research on the impact of sensory branding on the decision-making process for the purchase of a tourist product.

A wide field of interest and published papers result in membership in the publishing board of several international journals: Canadian Journal of School Psychology, Journal of Marketing Theory and Practice, Tourism and Hospitality Research, Journal of Biomedical Engineering and Biosciences, Advances in Agricultural Technology \& Plant Sciences, as well as and editorial position in the SciFed Journal of Global Warming.

Work experience: Long-term professor in several high schools, currently employed at the National University, and also engaged as a lecturer at the Faculty of Management, Sremski Karlovci, on the subjects: Management Marketing, Marketing Management, Human Resources Management, Communication, Small and medium-sized enterprise, Business Communication. 